\title{
Crítica de la Tesis de las Ideas Trasplantadas. Actores y Estrategias*
}

\author{
Danilo Martuccelli ${ }^{1}$ \\ Profesor de sociología en la Université de Paris e investigador en la Universidad Diego Portales. \\ E-mail: danilomartuccelli@gmail.com.
}

\section{INTRODUCCIÓN}

$\mathrm{U}$ n tópico crítico no cesa de recorrer el pensamiento social latinoamericano: muchas de las grandes representaciones que se emplean en la región no serían sino ideas trasplantadas. En este artículo propondremos un análisis crítico de lo que esta tesis afirma, su evolución, sus usos y las posibles razones de su permanencia. Con la noción de ideas trasplantadas reunimos pues, bajo un solo término, un gran número de expresiones afines, todas ellas designando, a través de una amplia polisemia e incluso ambigüedad, algo de substancial sobre la relación y el desfase entre las ideas y la realidad en América Latina.

Muchas de las nociones habitualmente empleadas para designar esta problemática están en efecto marcadas por una fuerte imprecisión. En Brasil, por ejemplo, la expresión "ideas fuera de lugar", acuñada en 1973 por Roberto Schwarz (2000), se impuso a pesar de los diversos malentendidos que originó (Cevasco y Ohata, 2002). De hecho, en un texto aclaratorio redactado cuatro décadas después, Schwarz se sintió obligado a precisar lo que quiso efectivamente decir: (1) la "impresión de que nuestras ideas, en particular las ideas adelantadas, no corresponden a la realidad local" (Schwarz, 2012:25); (2) la fuerte presencia de esta impresión entre los conservadores brasileños; (3) el sentimiento de que la implementación de ideas modernizadoras no reducía la brecha entre las ideas y la realidad, sino que incluso la ampliaba - el trabajo esclavo y negrero prosperó en Brasil notablemente durante el siglo XIX; *El presente artículo se inscribe en el marco del Proyecto de Investigación Fondecyt no 1180338 ,
"Problematizaciones del Individualismo en América del Sur". 
(4) "una innegable sensación de extrañeza y artificialidad" entre los miembros de las élites que adherían a las ideas progresistas. La conclusión: en Brasil, en el siglo XIX, a diferencia de Europa, "el liberalismo no describe ni de lejos el curso de las cosas - y es en ese sentido una idea fuera de lugar" (ibid.:26). En verdad, la tesis de Schwarz, así como sus propias aclaraciones, son profundamente ambiguas. Lo son al punto de que, en su esfuerzo por precisar el sentido de la tesis de las ideas fuera de lugar, Elías Palti (2014:35-44) concluye que esta señala simplemente la existencia de sentimientos, de contradicciones, de desajustes entre ideas "modernas" (o el desarrollo capitalista) y estructuras sociales "arcaicas" (como la esclavitud), algo que, como bien señala, no es en absoluto una especificidad latinoamericana.

Nuestro interés en este artículo no consiste en desentrañar el sentido específico de esta u otras formulaciones similares (ideas fuera de lugar, bovarismo etc.). Lo que nos interesa es utilizar la noción de ideas trasplantadas para problematizar las razones de la larga vigencia y seducción del aserto en las ciencias sociales y humanas en América Latina de la tesis de la inadecuación entre las ideas y la realidad. Con este objetivo nos desplazaremos desde el intento hermenéutico de precisar el sentido de estos asertos, hacia un estudio pragmático en función del uso que le dan sus principales enunciadores. Es desde la identidad de estos que nos parece posible establecer, distinguiéndolos, tres grandes fenómenos sociales que se dibujan detrás del recurso a la noción de ideas trasplantadas.

Desde esta perspectiva, tres actores y tres grandes actitudes o experiencias se destacan: la resistencia, la frustración y el encubrimiento. Por lo demás, aunque no hayan sido el único blanco de estas críticas, es evidente que desde la posindependencia han sido el liberalismo y la modernidad los que una y otra vez fueron juzgados como exógenos e importados, no genuinos, extraños a la región. Nada será más cuestionado que sus versiones abstractas del individuo y su voluntad de introducir instituciones artificiales en detrimento de los grupos reales. Por eso, aun si muchas de estas críticas no son más exclusivas del liberalismo que de cualquier otra ideología foránea (conservadora, fascista, socialista o marxista), dada la preeminencia de la hostilidad de la que la primera ha sido objeto en la región, la utilizaremos como señuelo a lo largo de nuestro estudio. 
He aquí la tesis central de este artículo: para analizar el decurso y vigencia de la tesis de las ideas trasplantadas es indispensable diferenciar tres grandes significaciones, pero sobre todo tres grandes tipos de actores en función de sus lazos con el liberalismo y la modernidad: opositores, liberales e intelectuales. Para los primeros, las ideas liberales serían extrañas a América Latina y su intento de aplicación habría despertado naturalmente resistencias. Para los segundos, las ideas liberales, que habrían sido orgánicas en Europa y en sintonía con las necesidades de la expansión del capitalismo, se habrían revelado infructuosas ante la realidad de los pueblos de la región. Para los terceros, el desfase entre las ideas y la realidad sería permanente a causa de distintos procesos históricos de encubrimiento identitario.

\section{LAS IDEAS TRASPLANTADAS Y LA RESISTENCIA}

En primer lugar, las ideas trasplantadas designan una actitud de resistencia que recorre el mundo desde fines del siglo XVIII y que probablemente tenga su verdadero bautizo en el libro crítico que, sólo un año después de la toma de la Bastilla en Francia, el conservador inglés Edmund Burke dedicó a la Revolución Francesa. La tesis: la revolución, en sus excesos intelectuales y artificiales, habría conspirado contra y cuestionado la realidad consuetudinaria de las relaciones sociales. Desde entonces, como lo mostró Albert Hirschman (1991), se trata de una de las grandes retóricas reaccionarias. El liberalismo y el republicanismo fueron, así, muchas veces descritos en la región como una ideología (en el sentido que Destutt de Tracy dio a este término): una representación propia a un grupo de intelectuales separados y extraños a la realidad social local.

El tropo critico conservador, incluso ampliamente transmutado, será permanente en América Latina y retomado por muchos críticos y opositores al orden republicano que se instituye tras la colonia. En Brasil, por ejemplo, muchos conservadores se opusieron a la Constitución de 1891 pretextando que introducía elementos importados y extraños a las tradiciones del país. En el mismo sentido, el conservador Lucas Alamán en su Historia de Méjico (1848-1852) acusa a las constituciones liberales de los principales males que aquejan a México desde la independencia. Una posición de esta índole también está muy presente, y de manera constante, en el pensamiento conservador chileno durante buena parte del siglo XX, como en Jaime Eyzaguirre quien en Hispanoamérica del dolor (1948) vitupera el carácter foráneo del liberalismo, 
ajeno al "alma colectiva" del continente, y denuesta el estéril afán imitativo que hizo que el hispanoamericano "ebrio de libertad /.../ se echó en los brazos de franceses e ingleses, para calcar sobre estos modelos su vida política" (citado en Correa Sutil, 2004:273). El oprobio de las ideas trasplantadas también está presente en el alegato caudillista de Laureano Vallenilla Lanz (1991) quien, en 1925, en su ensayo sobre el Cesarismo democrático, denuncia las constituciones de papel en nombre de las constituciones orgánicas y defiende a los caudillos como expresión auténtica de los pueblos latinoamericanos en oposición a los principios del liberalismo político.

Pero la tesis de la resistencia de la realidad local a las ideas liberales no solo fue evocada por conservadores o caudillo-nacionalistas, también lo fue por otros actores que cuestionaron las ideas trasplantadas como expresión de un conflicto de tinte civilizatorio entre la tradición y la modernidad. En esta variante, a veces, la resistencia al liberalismo y la defensa de la tradición llegaron a tomar la forma curiosamente - de una defensa de la herencia colonial y de sus formas corporativistas. Estas habrían permitido el mantenimiento de formas comunitarias indígenas (incluso desde concepciones "importadas" tomistas y corporativistas ibéricas), algo que las ideas foráneas de propiedad privada e individualistas del liberalismo y sus ataques a las comunidades no habrían permitido.

Notémoslo: si el recurso a la tesis de las ideas trasplantadas es común a estos actores y si, por lo general, se trata de una oposición a las ideas liberales, las razones y los procesos evocados no son los mismos. En un caso, a través de una retórica reaccionaria o conservadora se denostó el carácter importado, foráneo, inadaptado de la legislación liberal a las realidades de la región para defender jerarquías o corporativismos. En otros casos, se recurrió a la tradición como una manera de hacer frente al papel antipopular que el liberalismo y el capitalismo tuvieron en la región, en donde, por ejemplo, la expansión de la propiedad privada sirvió muchas veces de herramienta para expoliar de sus tierras comunales a los pueblos indígenas.

Este primer grupo de actores y usos de la tesis de las ideas trasplantadas no es en absoluto, a diferencia de los dos otros, una especificidad latinoamericana. Por eso, es importante revisar la geografía y la historia más amplia de este uso de la tesis. 


\section{LA GEOGRAFÍA HISTÓRICA DE LAS IDEAS TRASPLANTADAS}

Si hay indicios de la existencia del problema de la autenticidad (o sea, la tradición, las raíces, las ideas en su lugar) en América Latina desde la conquista y las colonizaciones ibéricas en el siglo XVI, es solamente en el siglo XIX ante la expansión del poder industrial y económico europeo, que la oposición a nivel mundial se estructura en estos términos.

Una de las primeras grandes defensas de la autenticidad tuvo lugar en Europa con los románticos quienes, desde el inicio de la industrialización, exaltaron las tradiciones y deploraron su destrucción. No es extraño, así, que sea en la estela del romanticismo, o de movimientos que tomaron prestadas más o menos explícitamente sus palabras, que se haya consolidado un fuerte y duradero rechazo a la modernidad (Mishra, 2017). En muchos de estos combates se trata de defender o restaurar un pasado destruido por la llegada de los occidentales - como en la tradición del buen salvaje, una invención occidental recurrente de Montaigne a Lévi-Strauss, pasando por Rousseau-; reivindicar una tradición amenazada por procesos de modernización, en nombre de la economía moral del precio justo como en los nacientes movimientos obreros en Europa (Thompson, 1988; Hobsbawm, 1966); o reinstaurar instituciones religiosas trastocadas por transformaciones políticas, como en las revueltas de la Vendée en Francia, Canudos en Brasil o los Cristeros en México. En este contexto ¿dónde está la especificidad de la tesis de las ideas "trasplantadas"? En que se trata de un recurso retórico y crítico particular: el rechazo no solo invoca la tradición, los cambios se rechazan porque se denuncian como inadaptados a la realidad.

No resulta nada extraño, por eso, que la tesis de las ideas trasplantadas haya sido activamente movilizada en defensa de la autenticidad contra la expansión de la modernidad occidental (Martuccelli, 2020). En muchos de estos debates existe así un conflicto entre dos perspectivas. Por un lado, élites modernizadoras y occidentalizantes que abogan por la necesidad de la industrialización y, para ello, por la adopción de las instituciones del Occidente moderno. Por el otro, otras élites, corporaciones o actores populares que pregonan la existencia de identidades o costumbres opuestas e inasimilables a los valores modernos y que denuncian el carácter foráneo y fuera de lugar de ciertas ideas. A ojos de los defensores de la autenticidad, el proyecto modernizador - más 
allá de los sufrimientos que conllevaba la imposición de instituciones extranjeras desprovistas de todo anclaje social y cultural efectivo - sólo podía fracasar.

La oposición entre la autenticidad y la modernidad occidental, gran variante planetaria de las ideas trasplantadas, tuvo distintas expresiones, pero en muchas de ellas se advierte una dicotomía de tipo nacionalista o civilizatorio. Esto es visible en la defensa que el arielismo latinoamericano hace de la autenticidad (una espiritualidad latina opuesta al materialismo estadounidense), o lo que en otras variantes se hace desde la religiosidad popular o los cimientos barrocos (Morandé, 1984; Véliz, 2011). Pero también lo es en ciertos enfoques decoloniales, con su crítica radical hacia la modernidad occidental (Escobar, 2011). Una oposición de este tipo está presente en muchas otras partes del mundo: en el paneslavismo (el combate entre los eslavófilos que encuentran la autenticidad del lado de la Iglesia ortodoxa y los pro-occidentales atraídos por la Ilustración); la Gran Turquía; el panarabismo o la importancia del tema de la autenticidad en la cultura árabe como un recurso para emanciparse de la cultura occidental importada (Corm, 2016); o en el panafricanismo de Nkrumah (1957-1966) en Ghana. En todos los casos, la autenticidad sirve para oponerse a la modernización foránea. Por eso, a pesar de profundas diferencias, una continuidad se perfila entre Rodó en América Latina, Gandhi en India y Sun Yat-sen en China (este último invocando la armonía confuciana), pero también con el asiatismo de Lee Kuan Yew en Singapur o Mahatir en Malasia (Brisson, 2018), o con Hasan al-Banna y los Hermanos musulmanes, desde 1928 en Egipto. En todos los casos, lo que se denuncia en nombre de la autenticidad son las ideas trasplantadas del Occidente moderno, liberal y materialista.

Sin embargo, si lo que se denunció fue el carácter foráneo de las ideas occidentales, lo que en verdad estuvo (y está) en debate fue (y es) la cuestión del cambio, su control y su metabolismo. Por eso, en la ruptura entre la modernidad y la tradición, la dificultad para metabolizar y controlar el cambio atraviesa y estructura también, profundamente, las sociedades occidentales. La cuestión de la autenticidad es también un debate intraoccidental. Desde el romanticismo y la lucha de clases hasta las oposiciones entre regiones o las guerras de religión, desde la discordancia de los tiempos hasta las reacciones contra el individualismo o el populismo y sus críticas reiteradas hacia la artificialidad de los intelectuales, la civilización moderna también ha sido teatro de oposiciones recurrentes de este tipo. 


\section{UN RODEO: APRENDIENDO DEL CASO JAPONÉS}

En vista de las maneras en que se inventan las tradiciones o se construyen por asimilación las identidades (Hobsbawm y Ranger, 2012; Bayart, 1996), la cuestión se impone tarde o temprano: ¿qué es lo propio y qué lo ajeno? ¿Durante cuánto tiempo una idea es ajena? El caso japonés es edificante a más de un título para abordar esta problemática.

Siendo la primera sociedad no occidental que logró verdaderamente industrializarse, Japón fue, con una rara intensidad, el escenario de un gran debate entre la modernidad y la autenticidad. El gran interrogante consistió en saber si la modernización del país significaría o no su inevitable occidentalización. La modernización japonesa articuló muchas características comunes con otras experiencias - como la construcción de un Estado centralizado y la creación de un sistema educativo eficaz, vía un sistema político despótico a la prusiana - y sus expresiones específicas, el ethos confuciano o el individualismo honorífico samurái (Souyri, 2016; Morishima, 1982; Ikegami, 2012). Las oposiciones no solo se desencadenaron en nombre de la autenticidad cultural, sino que fueron parte de conflictos propios de la sociedad japonesa, comenzando por la oposición entre la lógica de un Estado poderoso, por un lado, y la reivindicación de derechos, por el otro. Los defensores de los "derechos del Estado" ("amor al país", "lealtad al soberano") se inscribían en la estela de ciertas tradiciones culturales japonesas (armonía, reserva, moderación, deferencia), mientras que los partidarios de los derechos del pueblo y de la libertad se apoyaron en otros frentes culturales, como la vulgarización de los temas de la Ilustración, pero también la referencia a ciertos modelos chinos (Souyri, 2016:163 y 167).

Al menos hasta su victoria sobre Rusia en 1905, Japón osciló entre Occidente, fascinante y amenazante, y Oriente, con China como utopía (Devés, 2017:172-176). Sin embargo, en el marco de la Revolución Meiji (1868), ya en la década de 1890 y a medida que el industrialismo se desarrollaba, se propagó el sentimiento de que para lograr la "civilización" era necesario distanciarse de China y Corea y de sus "viejas costumbres". Un slogan resumió este movimiento: había que decir "adiós a Asia y buenos días a Europa".

En verdad, la occidentalización nunca dejó de ser objeto de discusión. La reacción a la imitación de la Ilustración dio así lugar a un movimiento de defensa y reinvención de una identidad japonesa, una iden- 
tidad que, contra la universalidad, defendió lo particular y la voluntad de afirmar la nación japonesa tanto contra Occidente como contra Oriente. Ese fue el título de un célebre coloquio que tuvo lugar en 1943: "Superar la modernidad". Tanto los partidarios del niponismo como los románticos, marcados por tensiones nostálgicas hacia el pasado y la genuinidad, defendieron un nacionalismo opuesto a la modernización y las ideas trasplantadas sobre las que se apoyaba. Estos movimientos propusieron el rechazo de todas las ideologías modernas occidentales (incluidas el marxismo y el liberalismo) y el regreso a las doctrinas tradicionales con el fin de hacer de Japón el portaestandarte de la resistencia asiática a la modernidad (Stevens, 2018:24).

Dentro de estos debates es interesante traer a colación el trabajo de Masao Maruyama, uno de los más importantes filósofos japoneses del siglo $\mathrm{XX}$, porque supo reivindicar mejor que muchos otros las raíces tradicionales de una modernidad específicamente japonesa. En su Ensayo sobre la historia del pensamiento político en Japón publicado en 1952, Maruyama (2018) se esfuerza por mostrar la existencia de elementos autóctonos, o sea genuinos, que testimonian una auténtica aspiración japonesa a la modernidad. Para Maruyama, la oposición entre el "autocratismo tradicionalista japonés" y la "emancipación modernista occidental" era una falacia. Para él, es en nombre de una inquietud confucionista tradicional hacia el bien común y la lealtad hacia Japón, en virtud de un sentido del deber desinteresado por la nación, como se abrirían los caminos de la modernización y de la emancipación en el país.

¿Por qué traer rápidamente a colación el debate japonés por sobre tantos otros similares? Por un lado, porque el llamado a la nación japonesa es un caso notorio de las defensas que un colectivo puede organizar en torno a la autenticidad para hacer frente a los malestares inducidos por el cambio social. Por otro lado, y aquí está en verdad lo esencial, porque la historia japonesa da el primer gran contraejemplo de un país que logró industrializarse de manera inédita y más precoz que cualquier otra sociedad no occidental. A lo largo de este proceso de modernización, la tesis de las ideas trasplantadas conoció diversas versiones. Primero, con la Revolución Meiji se impuso la idea que para salvaguardar la independencia del Japón era indispensable modernizar el país abrazando enfáticamente las instituciones fuera de lugar occidentales. Segundo, frente a esta occidentalización rampante, otra parte de las élites denunció, en nombre de la tradición (las ideas en su lugar), las instituciones foráneas que intentaban imponerse. Ter- 
cero, los modernizadores replicaron mostrando la existencia de bases tradicionales sobre las cuales se apoyaba, prolongaba o reinventaba la modernidad japonesa. Una dimensión que, durante todo el siglo XIX y buena parte del siglo XX, no se dio en América Latina, a causa justamente de la modernidad dependiente que hubo en la región, y de la ausencia, con respecto al caso japonés, de un Estado nacional administrativamente eficaz. Cuarto y lo más importante: aunque estos debates no han desaparecido, el que Japón sea hoy un país altamente industrializado (y rico), permite que muchos actores se perciban, sin tensión, como modernos sin ser occidentales. Esto es lo esencial: el fuerte debate identitario que se apoderó del país desde finales del siglo XIX y durante gran parte del siglo XX ha dado paso a la relativa calma identitaria del Japón actual. Una situación que ha disuelto ampliamente las polémicas sobre las ideas trasplantadas.

Esto, hasta la fecha, no se ha dado realmente en ningún país de América Latina y da cuenta de la vigencia y del recurso estratégico que desde distintas formas de resistencia se oponen, en nombre de la autenticidad, a las ideas trasplantadas. Sin embargo, en su decurso, la historia de América Latina invita a análisis más desapasionados, aunque mal no sea porque, incluso tomando los cánones de la autenticidad, si el liberalismo está fuera de lugar, no lo está de la misma manera en todos los países. En México, por ejemplo, si la tradición liberal es muchas veces - no siempre, no para todos - reconocida como parte del legado institucional del país, en la Argentina - pero solo después de la década de 1930 -, este legado y su "autenticidad" local sólo es reconocido por ciertos actores políticos e intelectuales. Halperin Donghi (2017:144) arriesgó una interpretación: "mientras el repudio cada vez más abrumador que pesa sobre el liberalismo argentino se apoya sobre todo en la supuesta ausencia de una dimensión nacionalista en su ideología", en México el liberalismo "conserva casi intacto su imperio sobre la conciencia colectiva [porque] se define como orgullosamente nacionalista". Complementando esta interpretación, para dar cuenta de esta misma dicotomía Miguel Rojas Mix (2018:91) evoca el contraste entre el proyecto liberal "mestizo" presente en México, que le otorga un papel fundamental al mestizo como dinamizador de la nacionalidad, y el proyecto liberal "criollo", presente en Argentina, no democrático y anti-mestizo.

En sentido análogo, la existencia de un republicanismo o liberalismo popular desde el siglo XIX en América Latina también cuestiona el supuesto carácter perdurablemente "ajeno" de estas corrientes. 
La prueba de su arraigo es visible entre la población de origen africano en su lucha contra la esclavitud o la explotación en Colombia (Sanders, 2004); entre sectores campesinos e indígenas en México o Perú (Knight, 1985; Méndez, 2014; Mallon, 1995); en el republicanismo popular decimonónico de Santiago Ramos (2017), "El Quebradino" en Chile; en el impacto que tuvo en Perú la retórica liberal-republicana entre artesanos, labradores y gente de color en el siglo XIX (McEvoy, 2011; García-Bryce Weinstein, 2008) y en muchas milicias decimonónicas de ciudadanos (Sabato, 2018).

La identidad, como se sabe, es hacer lo propio con lo ajeno. Arraigar ideas foráneas. Este también ha sido el destino, con tensiones, de la modernidad en América Latina. Y una de las razones del uso estratégico de la tesis de las ideas trasplantadas.

\section{LAS IDEAS TRASPLANTADAS Y LA FRUSTRACIÓN}

Si el recurso a la autenticidad en contra de la modernidad es común a muchas otras partes del mundo e, incluso, ha tenido en otras regiones sus principales protagonistas (conservadores europeos o perspectivas antioccidentales), la segunda variante de la tesis de las ideas trasplantadas no solo es propia de América Latina, sino que introduce una sorpresa y una cierta especificidad: los principales liberales y republicanos del siglo XIX fueron grandes actores y sostenedores de la tesis de las ideas fuera de lugar. ¿Cómo explicarlo?

En la base de este segundo recurso a la tesis se encuentra una experiencia de frustración: la de todos aquellos que, adhiriendo a las ideas liberales, constatan su insuficiente o inadecuada aplicación en la realidad. El rechazo o la resistencia "telúricas" presentes en el grupo anterior ceden el paso a interpretaciones más puntuales, a medida que los críticos adhieren a los valores liberales, por ejemplo, en la (des) calificación que Raúl Ferrero hace del liberalismo peruano como una:

(...) utopía al imaginar "repúblicas aéreas", con instituciones no adaptables a nuestro medio, de desconocimiento del país real, de exceso de lenguaje doctrinario, de ignorancia de las condiciones sociales y de las necesidades de las provincias, de superstición parlamentaria, de vaguedad en el americanismo sentimental que proclamara (Ferrero, 1958:37). 
La interrogación se desplaza hacia las razones de la "infertilidad" del liberalismo en América Latina.

Esto es relevante para el análisis: entre muchos liberales latinoamericanos hubo una reflexión sobre las limitaciones del liberalismo que muchas veces adoptó la tesis de la inadaptación de las ideas liberales a la sociedad real. La tesis ya está presente, con variantes, más en Bello que en Sarmiento, tanto en Bolívar como en Santander.

\section{LUCIDEZ Y AMBIVALENCIAS DE LAS ÉLITES}

El proyecto modernizador de las élites no estaba fuera de lugar. Por el contrario, lectores asiduos de Montesquieu, muchos liberales y republicanos decimonónicos no ignoraban en absoluto que "las leyes deben ser adecuadas al pueblo para el que fueron dictadas, de tal manera que solo por una gran casualidad las de una nación pueden convenir a otra" (citado en Botana, 2013:36).

Retrospectivamente, lo que impacta es tanto la precocidad como la reiteración de este ítem. Una denuncia de esta índole, por ejemplo, ya está claramente presente, jen 1812!, en el chileno Camilo Henríquez (2011) quien en su texto "El espíritu de imitación es muy dañoso a los pueblos" llega incluso a explicar los "disturbios" de Haití - la liberación de los esclavos - por esta razón: "si el pueblo es de costumbres feroces, se verá la anarquía acompañada de atrocidades; y esto sucedió en la revolución de la isla de Santo Domingo" (ibid.:51). Desde entonces, el peligro de la imitación nunca dejó de ser periódicamente actualizado.

Juan Bautista Alberdi (2008:82), por ejemplo, es muy crítico de la artificialidad de las constituciones adoptadas en Argentina hasta antes de 1852: a sus ojos era indispensable "dar pobladores a estos desiertos [americanos]" y "formar caminos de hierro" para suprimir "las distancias que hacen imposible esa unidad indivisible en la acción política que con tanto candor han copiado nuestras constituciones de Sud América de las constituciones de Francia, donde la unidad política es obra de ochocientos años de vida preparatoria". Ocho siglos: aquí está lo esencial. La realización del proyecto republicano y liberal llevaría tiempo. Alberdi, en 1855, explicita, bajo esta impronta, el inevitable divorcio: "La libertad, viva en el texto escrito y maltratada en el hecho, será por largo tiempo la ley de nuestra condición política en América antes española" (citado en 
Botana, 2012:57). También en el Facundo de Sarmiento (2008), publicado en 1845, una conciencia de esta índole está presente: si los "bárbaros" habían llegado al poder (con Rosas) esto se debía al error de muchos "civilizados" que habían pretendido importar modelos europeos sin tomar en cuenta la realidad particular - la barbarie - del mundo donde esos discursos debían operar (Ramos, 2009:73). En el mismo sentido, en México, desde las primeras décadas del siglo XIX, el liberal José Luis Mora habló de la "locura" de constituciones inadaptadas a la realidad "despótica" del país (Hale, 2012:108 y siguientes). Y desde Chile, el conservador-liberal Andrés Bello, concuerda con ello:

(...) si hay algo completamente demostrado por la experiencia del género humano (...) es que no debe esperarse subsistencia ni buenos efectos de ninguna constitución modelada por principios teóricos, sin afinidad con aquellos que por una larga práctica han adherido íntimamente al cuerpo social (Bello, 2011a:74).

Es este divorcio entre las ideas y la realidad, y la inteligencia de este divorcio dentro de los miembros de la élite, lo que malentiende la crítica de las ideas trasplantadas. El liberalismo latinoamericano sabía que era ajeno a la realidad de los países de la región, era, en el sentido más neto del término, un proyecto. Dada la representación que tenía de los pueblos latinoamericanos, pensó que ello requería su más o menos larga puesta bajo tutela (comenzando, por ejemplo, por diferir el derecho de voto de los analfabetos durante algunas décadas tras la independencia). Es pues, desde esta posición como deben entenderse muchas de las medidas que implementaron y lo que los llevó a oponerse a los corporativismos (Iglesia, ejército, gremios) o a las comunidades indígenas con el fin, justamente, de imponer instituciones individualistas que consideraban modernas y necesarias para asegurar el progreso material.

En este contexto, nada ejemplifica mejor la postura de muchos de estos liberales y republicanos que la tensión entre lo que (probablemente de forma honesta) querían hacer y lo que pensaban que se podía hacer. La prudencia fue así el gran talante político, ampliamente compartido. Un célebre pasaje de una carta de Diego Portales, en Chile, a inicios de la década de 1830, expresa cabalmente una primera actitud:

La democracia que tanto pregonan los ilusos es un absurdo en países como en los americanos, llenos de vicios y donde los ciudadanos carecen de toda virtud, como es necesario para establecer una verdadera república (...). 
Cuando se hayan moralizado, venga el Gobierno completamente liberal, libre y lleno de ideales, donde tengan parte todos los ciudadanos (citado en Rojas Mix, 2018:92-93).

Una actitud similar, pero ya más matizada en su prudencia, es observable en Andrés Bello (2011b:103) quien, a propósito del Código Civil chileno de 1857, afirma en perfecto acuerdo con la cita ya evocada de Montesquieu que "el movimiento social debe influir en las leyes civiles; los legisladores deben modificarlas para ponerlas en armonía con él", lo que, desde su visión, podía justificar, retrasar o postergar la aplicación de ciertas medidas en nombre del imperativo del orden. En fin, es justamente esta espera (el "largo tiempo" del que habló Alberdi en 1855), lo que el liberal chileno Lastarria (2011:142) - en 1868 - considera criticable: a sus ojos no se puede considerar como bueno un gobierno que "no nos dé nuestros derechos". Detengámonos en este punto. La impaciencia de Lastarria le lleva a descartar, en nombre de la realidad, las objeciones de sus opositores: contra aquellos que juzgan ilusorio darle derechos políticos al pueblo, Lastarria recuerda que ya son "sesenta años" que el pueblo de Chile no vive bajo "la condición abyecta de la esclavitud y de la ignorancia" en que se hallaba bajo el régimen colonial. Incluso más: “ ¿No hace más de medio siglo que usa, sin peligro, de todos sus derechos civiles, de todas las condiciones de la civilización, y que juega a las farsas republicanas?" (Ibid.:145).

¿Qué retener de este común reconocimiento del valor de la prudencia? Que entre la mayoría de los miembros de la élite siempre estuvo presente la necesidad, en el momento de redactar las constituciones, de tener en cuenta las realidades idiosincráticas de los pueblos latinoamericanos. Si voluntarismo hubo, este siempre fue muy bien temperado. Esto obliga a matizar ampliamente la tesis según la cual los liberales decimonónicos fueron ideólogos alejados - o ignorantes - de las realidades sociales de sus países.

¿De dónde procede entonces la seducción de la tesis de las ideas fuera de lugar? De la conciencia que tienen las élites posindependencia de la auténtica revolución que efectúan a nivel del imaginario social. A saber: el tránsito de un mundo corporativista a una sociedad moderna de individuos (Guerra, 2014). Un trabajo institucional de invención para el cual, como lo reconoció Bello (2011a:75), "en los materiales que el régimen colonial de España había dejado a nuestra disposición, había poco o nada de que pudiésemos aprovecharnos para formar constituciones 
populares y libres". En un sentido análogo, en 1850, reconstruyendo sus vivencias de ese momento en Recuerdos de Provincia, Sarmiento escribe que si Norte América se separó de Inglaterra sin renegar de sus instituciones, "nosotros, al día siguiente de la revolución, debíamos volver los ojos a todas partes buscando con qué frenar el vacío que debían dejar la inquisición destruida, el poder absoluto vencido, la exclusión religiosa ensanchada" (citado en Botana: 2013:220).

Esta experiencia da cuenta, al menos parcialmente, de las razones por las que el liberalismo se sirvió del tópico de las ideas trasplantadas: como resultado de la tensión entre la invención y la prudencia. Sin embargo, bien vistas las cosas, más allá de ciertos momentos doctrinarios muy cortos, la prudencia ante los imperativos de la realidad marca durable e infinitamente más a los liberales latinoamericanos que su ebullición doctrinaria.

¿El liberalismo, como proyecto fundacional, introdujo distorsiones entre los principios y la realidad? Por supuesto. Pero los actores de la época eran plenamente conscientes de ello. Incluso puede decirse que lo eran de dos maneras. Por un lado, a sus ojos la República era un proyecto que no tenía reales bases en la región, pero sobre las cuales había que edificar, con prudencia, un nuevo orden institucional. Por otro lado, las élites no solo eran conscientes del desfase entre los ideales y las realidades sociales, sino que también estaban convencidas de que esta tensión no era en absoluto exclusiva de América Latina. Bello (2011c:81) es explícito: “ise podrá nunca imaginar un fenómeno más raro que el que ofrecen los mismos Estados Unidos en la vasta libertad que constituye el fundamento de su sistema político y en la esclavitud en que gimen casi dos millones de negros bajo el azote de crueles propietarios?". Difícil ser más elocuente en la crítica en lo que respecta a una supuesta especificidad de las ideas trasplantadas en América Latina. A su manera incluso puede decirse que, en este punto, Bello le responde por anticipado (casi 180 años antes) a Schwarz.

\section{FRUSTRACIONES Y JUSTIFICACIONES}

Si lo anterior precisa el sentido estratégico de este uso de la tesis de las ideas trasplantadas, no responde enteramente a la pregunta de por qué los liberales latinoamericanos fueron tan proclives a ella. ¿Por qué 
en sus momentos de frustración, desde Bolívar y su sentimiento de la América errada, las élites latinoamericanas recurren cíclicamente a la figura de las ideas trasplantadas?

Para comprender la especificidad de esta frustración es preciso entender bien el problema y salir de la mera constatación de una "contradicción" entre los ideales igualitarios que profesaban las élites y sus prácticas sociales. ¿Cómo descuidar el hecho de que la universalidad de los Derechos del Hombre y del Ciudadano fue infinitamente mejor traducida y practicada, en lo que concierne a la esclavitud, por ejemplo, en Haití a comienzos del siglo XIX que en Francia? ¿Cómo descuidar que, salvo Brasil y Cuba, los países latinoamericanos abolieron la esclavitud antes que los Estados Unidos? Si traemos a colación nuevamente lo anterior es solamente para contrarrestar una visión demasiado pesimista sobre los alcances del liberalismo en la región, pero también porque nos indica por dónde no hay que buscar las razones de la permanencia de este sentimiento de extrañeza entre ideas y realidad entre los miembros de la élite.

En el corazón de la dinámica de la democracia (y de su versión liberal en los tiempos modernos) se encuentra la distancia, constante y más o menos amplia, entre los principios y la realidad. Esta distancia constituye un recurso permanente, no exento de retrocesos, por el cual se intenta equiparar progresivamente los ideales con la realidad. Si los tiempos y la profundidad de los desfases varían, América Latina no tiene en este registro ninguna particularidad. O si la hay, la variación puede ser de grado y de ritmo, no de naturaleza. Las ideas liberales e igualitarias, por ejemplo, también tuvieron un rol revolucionario en la región, como lo advirtió Florestan Fernandes (1975): a pesar de los innumerables compromisos que se dieron entre los ideales y la realidad de la esclavitud en las plantaciones, el liberalismo tuvo a la larga, en lazo con muchos otros factores, un papel en la abolición de la esclavitud en Brasil. No es ni una constatación aislada, ni una observación sin sustento histórico. El reconocimiento de la distancia entre el ideal y la realidad también fue, por ejemplo, una de las grandes razones que se invocaron para hacer avanzar el derecho de voto. En un texto de inicios del siglo XX, Valentín Letelier, miembro del Partido Radical, y propulsor de la "cuestión social" en Chile, llamaba así la atención sobre una tensión de este tipo: "mientras el derecho nos halaga con la ilusión de que vivimos en una perfecta democracia, el derecho real nos tiene sujetos a una oligarquía corrupta y diminuta" (citado en Aljovín de 
Losada y Araya, 2006:200). Una constatación que, como se desprende del texto, se usa como herramienta para profundizar la concretización del imaginario social igualitario individualista.

O sea, la distancia entre el país real y el país legal, entre el derecho y los hechos, entre lo formal y lo real no es en absoluto una especificidad de la historia latinoamericana. Esta distancia no solo fue un obstáculo, por lo general sirvió como un recurso para la adquisición de nuevos derechos y la transformación de la realidad. En muchas sociedades y periodos los derechos se expresan y se reclaman antes de que logren materializarse; muchas veces son las contradicciones entre los derechos y los hechos lo que lleva, progresivamente, a la transformación de estos; $y$, tal vez aún más importante, son las expresiones de universalidad contenidas en el derecho las que, aun lentamente, a través de ampliaciones sucesivas en dirección a otros grupos sociales (étnicos, mujeres, jóvenes), han sido un agente efectivo de cambio social.

La historia, bajo esta coordenada, se lee como un progreso permanente. En esto radica, tal vez, la especificidad de la seducción de las ideas trasplantadas entre las élites latinoamericanas. Su adhesión a la tesis de la artificialidad de las ideas (liberales) da cuenta del insuficiente dinamismo, a sus ojos, de la tensión virtuosa de los ideales con la realidad. Desde los inicios de las Repúblicas, la materialización de los ideales estuvo bajo sospecha. O sea, para la élite, la tesis de las ideas fuera de lugar sirvió como exutorio para expresar un sentimiento de frustración colectiva frente a la exigüidad de las transformaciones y resultados que in fine se habían alcanzado desde la posindependencia.

O sea, la durabilidad del sentimiento de las ideas trasplantadas entre las élites resulta de la larga dificultad de imponer plenamente su hegemonía en los hechos. Esta distancia, común a muchos otros países y períodos, no se resolvió en América Latina ni en un proyecto modernizador logrado (como en Japón, disolviendo la cuestión de la autenticidad) ni en una actitud plenamente antimoderna (como en tantas otras regiones del mundo desde una defensa acérrima de las tradiciones). En este intermedio quedó el recurso retórico y estratégico del divorcio entre el país real y el país legal, una fórmula en la cual pudieron coincidir muchos miembros de la élite modernizadora frustrados por los alcances efectivos del liberalismo. 
Se trata de un sentimiento recurrentemente alimentado por los temores y los estereotipos que las élites latinoamericanas no han dejado de tener respecto del pueblo. El ideal del ciudadano que tuvieron los más conspicuos liberales del siglo XIX (un ciudadano educado y propietario agrícola, esclarecido e innovador, dotado de inteligencia práctica) se opuso fuertemente a la representación que tuvieron de los habitantes de sus países - "bárbaros". Esto imponía la necesidad de cambiar las costumbres, de educar, incluso de trasplantar pueblos nuevos.

Notémoslo: a través de estos estereotipos, a su manera, las élites latinoamericanas fueron activas constructoras de las bases mismas de la tesis de las ideas trasplantadas. ¿Cómo, dada la realidad de pueblos atávicos y con tendencias "orgánicas" al caudillismo, formar la nación y asentar la República? En el fondo, en este punto, la inquietud de los conservadores o liberales es gemela en Portales o Sarmiento, en Bolívar o Alamán. Sin embargo, si en esta representación del pueblo la élite liberal comulga con los conservadores, lo hace con una diferencia y es de talla: para los liberales esta realidad inicial, de hecho, no tenía que ser necesariamente la realidad final, de proyecto. Al contrario, es contra la barbarie, pero teniéndola en cuenta, que tenía que construirse el entramado institucional de las Repúblicas latinoamericanas. Pero cada vez que el malestar se impone entre las élites, cada vez que ven sus designios cuestionados o rechazados, la tentación del recurso a la tesis de las ideas trasplantadas resurge como una justificación exculpatoria de su propia (in)acción.

En breve: la tesis de las ideas trasplantadas le sirve a la élite como justificación crítica de sus límites modernizadores y como mecanismo de refuerzo de su concepción estigmatizadora de los pueblos latinoamericanos.

\section{LAS IDEAS TRASPLANTADAS Y EL ENCUBRIMIENTO}

La tercera variante de la tesis de las ideas trasplantadas arraiga en el durable sentimiento de artificialidad que acecha a los intelectuales latinoamericanos. En este tercer grupo de actores se impone la idea de una dificultad o incapacidad congénita a la hora de aprehender América Latina, a causa de profundas experiencias de encubrimiento. Esto se traduce en el reiterado exordio de la necesidad de pensar "desde" América Latina y sus realidades, necesidad que, frente a la persistencia de este sentimiento, cada nueva generación de intelectuales va a enunciar como un imperativo y una novedad radical. Una problemática 
resume mejor que muchas otras esta inquietud: el tema de la identidad de los latinoamericanos. Tras ella, lo que se revela, muchas veces, es la representación de un divorcio entre los que se es y las apariencias. Pero ¿de dónde viene la persistencia de este sentimiento? A propósito de esta dimensión, hay que distinguir dos cuestiones.

\section{LA CONVICCIÓN DE LO INAPREHENSIBLE}

Esta variante de la tesis de las ideas trasplantadas posee una innegable especificidad regional. Si no es exclusiva de América Latina, el hecho que tras la conquista o la independencia se produjeran alternativas institucionales - primero a las comunidades indígenas sobre la base de las jerarquías corporativas ibéricas, luego, siglos después, al orden colonial alrededor de la soberanía popular y la matriz jurídica igualitaria individualista - habría dado lugar a tenaces procesos de encubrimiento y a una realidad inaprehensible. Entre muchos intelectuales se impuso un sentimiento de extrañeza, de artificialidad, de inconsistencia, de bovarismo, el sentimiento que las ideas no logran nunca aprehender plenamente la realidad y que están fuera de lugar. Notemos que si en este caso a veces se contrapone lo nacional y lo extranjero, en el fondo lo que se expresa es otra cosa, más profunda y menos precisa, un sentimiento de inadecuación generalizada de las ideas y la realidad.

Aunque en lazo con las utilizaciones anteriores, la perspectiva toma aquí un cariz más heurístico. Este anhelo y este horizonte está presente como un programa, por ejemplo, en el peruano José Carlos Mariátegui (1987:249):

No queremos ciertamente que el socialismo en América sea calco y copia. Deber ser creación heroica. Tenemos que dar vida con nuestra propia realidad, en nuestro propio lenguaje al socialismo indoamericano. He aquí una misión digna de una generación nueva.

Esta perspectiva también estuvo muy activa en el grupo Fuerza de Orientación Radical de la Joven Argentina (FORJA) en los años 1930 en Argentina, el que reivindicó la necesidad de "ver la Argentina desde la Argentina, en función de su realidad y sus necesidades inmediatas, y no desde afuera, en función de doctrinas abstractas, de ideologías transferidas desde el exterior en función de realidades y necesidades 
ajenas" (Jauretche, 1984:53). En una veta similar Ángel Rama (2004:134) llegó a cuestionar en 1984 la tendencia a la "imitación directa, incomprensiva de las tradiciones seculares del continente" que practicaron los primeros liberales y que "sólo se volvió a repetir entre los anarquistas que trasladaron tal cual sus fórmulas europeas nacidas de la industrialización del siglo XIX"1.

Lo que asombra es - como a propósito de los conservadores o las élites liberales - la reiteración de esta crítica y su circulación entre intelectuales muy disímiles entre sí, cada cual expresando a su manera una sensación generalizada de desfase entre las ideas y la realidad. Ya en 1917, Antonio Caso designará, por ejemplo, al bovarismo como un gran rasgo de la cultura mexicana: el anhelo de concebirse distinto a como se es. Ésta es una perspectiva que tuvo otra versión en la crítica que José Joaquín Brunner (1992) hizo al "macondismo" regional, en donde el bovarismo empalma con el realismo mágico, lo real-maravilloso y con la incapacidad de los latinoamericanos de asir la realidad. Los términos y las críticas se multiplican, resta lo esencial: en todos se trata de mentar el desfase inagotable entre las palabras y las cosas, las miradas y los hechos. Incluso en las muchas veces muy justas críticas que se dirigen al eurocentrismo - como en Leopoldo Zea (1965) - es posible reconocer una experiencia del pensar que se representa como estrellándose contra una realidad inaprehensible.

Nada lo ejemplifica mejor que la larga tradición de reflexión sobre el ser y el carácter nacional. Un conjunto de ensayos de corte filosóficoliterario, con tinte existencial, que incluso en medio de fuertes desacuerdos comparte un cierto talante intelectual en su búsqueda por desentrañar las raíces del ser y de la identidad. Una lista no exhaustiva de autores que va desde los argentinos Martínez Estrada, Eduardo Mallea, Héctor Murena, Rodolfo Kusch a los grandes "intérpretes" de la realidad nacional brasileña (Oliveira Vianna, Giberto Freyre, Caio Prado Júnior o Sérgio Buarque de Holanda), cada uno de ellos desde bases distintas esforzándose por desentrañar y diagnosticar el "alma" del país. Por contraponer como, por ejemplo, en Buarque de Holanda (1995) un Brasil ideal y un Brasil real, diseñando un conflicto entre las instituciones liberales copiadas del exterior y las realidades concretas de un país en donde los individuos se caracterizan por una emotividad y una cordialidad muy distinta a la racionalidad del burgués liberal. Una lista a la que habría que añadir en México, entre otros, a Samuel Ramos, Octavio Paz e incluso Bonfil Batalla, cada cual intentando com- 
prender la personalidad del mexicano desde su sentimiento de inferioridad producto de sus metas exageradas en su intento de imitar otros pueblos más desarrollados; desde su vergüenza y duplicidad por ser el hijo de una madre violada; o desde la resistencia inveterada de un país profundo. Desde variantes muy distintas, lo que es común a estos trabajos es la descripción de la identidad desde su "encubrimiento", y una búsqueda constante por develar el país real, auténtico, esencial, a veces invisible, siempre profundo.

En breve: más allá de las muy notorias diferencias entre los autores que hemos evocado, y que podrían multiplicarse a voluntad, lo esencial es el sentimiento tan arraigado entre los intelectuales latinoamericanos de una cierta incapacidad a la hora de asir la realidad, sobre todo de la necesidad de un trabajo heroico para, sin mimetismos, lograr capturar la identidad o la esencia encubiertas del continente.

Este tercer recurso a la tesis de las ideas trasplantadas se apoya, así, en una interrogación lancinante de factura ontológica, existencial, identitaria sobre el ser de los latinoamericanos. A un cierto nivel, este sentimiento puede leerse como lo propio de una intelligentsia que durante mucho tiempo contó con escasos o sesgados asideros en la realidad social (pocas instituciones culturales, exiguo público lector, insuficiente campo intelectual, cf. Botelho, 2019), más que como el fruto de un desarraigo primigenio. Esto, sin embargo, no elude formular - meta-teóricamente - una interpretación sobre las razones, dada la permanencia de este sentimiento, de la construcción de esta tradición, de este mito (o sea, discurso sobre los orígenes), de la reiteración del tópico de la necesidad de pensar desde América.

\section{LO ORIUNDO Y LO DESEABLE}

Incluso aceptando el postulado, altamente impreciso y polémico, de una realidad encubierta e inaprehensible ¿qué tan importante es, en lo que a su pertinencia analítica se refiere, la cuestión de la oriundez de las ideas? La pregunta aborda la cuestión del suplemento heurístico que las ideas "propias" tendrían a la hora de asir la realidad, pero también - lo que es tal vez incluso más importante - sobre el surplus de valor que las instituciones, por ser auténticas y oriundas, tendrían. 
Medido con este rasero, es importante - por ejemplo, como lo hicieron Maruyama y tantos otros - mostrar, frente a la arrogancia del relato hegemónico occidental moderno, la existencia dentro de varias tradiciones nacionales de instituciones "modernas" o "igualitarias", de tolerancia hacia la religión, valorización de la pluralidad, así como períodos de apertura o de cierre en todas las sociedades. Amartya Sen (2006:27) recuerda, por ejemplo, el destino del judío Maimónides que se escapa de una Europa intolerante para encontrar refugio en el mundo árabe. En un sentido análogo, también es importante recordar la existencia de una vasta tradición de debate público sobre problemas políticos, sociales o culturales en China, Japón, Corea, Irán, Turquía, el mundo árabe o en muchas regiones de África y su tradición de la palabra (ibid.:16; Bidima, 2015).

Pero esta revisión histórica cambia subrepticiamente de sentido cuando la crítica al eurocentrismo se transforma en una actitud axiológica. Los partidarios de la oriundez de las ideas (y de las instituciones) a menudo confunden la segunda con la primera operación, transformando, muchas veces sin suficiente examen, lo oriundo, porque auténtico, en una realidad a la vez inevitable y deseable.

En última instancia, la interrogación gira en torno al valor que se otorga a la invención oriunda. Sea o no que la democracia se inventó en la Grecia antigua, esto no cuestiona, por ejemplo, el hecho que la democracia es un régimen político muy expandido históricamente, que conoció sus formas más profundizadas en otras regiones y mucho más tarde, y del que se puede, o no, ser un partidario independientemente de la cuestión de su origen. La historia del mundo está hecha de préstamos (e imposiciones) institucionales y es importante por eso que los problemas y las rivalidades identitarias no falseen legítimos debates históricos. El supuesto carácter importado y artificial de las instituciones es muchas veces un falso debate. A lo largo de la historia muchas sociedades han sabido metabolizar formas institucionales externas con el fin de producir lo propio y la ilusión de lo oriundo. Esto se aplica tanto a los modos de gestión griegos incorporados por Roma como a la (re)invención de la democracia en el Occidente moderno (de las ciudades italianas a la Revolución Francesa o Americana); tanto a la penetración del capitalismo (y antes, del comunismo) en China como a la creación política de los Estados nacionales sobre la base de las fronteras heredadas de las colonias españolas y portuguesas en América Latina, etc. 
Si el terreno es resbaladizo, es porque gran parte de los trabajos que buscan redescubrir lo oriundo son muchas veces una respuesta a las lecturas peyorativas que se produjeron desde el relato hegemónico occidental moderno y de las cuales es indispensable deshacerse. Pero hacerlo invocando su artificialidad supone adherir, incluso involuntariamente, a la larga tradición de las ideas trasplantadas, perdiéndose así el legítimo derecho de elaborar un inventario crítico. Lo supuestamente oriundo, lo propio, se vuelve un destino. Esto lleva a algunos intelectuales a abrazar una posición de resistencia radical ante las ideas trasplantadas, ampliamente asociadas por lo demás con los valores hegemónicos o las instituciones occidentales modernas. Aunque marginal, esta postura radical aparece por momentos en América Latina cuando se (re)inventan tradiciones precolombinas - oriundas - en lucha centenaria contra la imposición occidental (Flores Galindo, 1988; Bonfill Batalla, 1987); pero también en ciertos movimientos nativistas indígenas excluyentes. Otros, por el contrario, pero siempre en este marco de pensamiento, se esfuerzan por mostrar - en analogía a lo que hizo Maruyama en Japón - frente a las lecturas jerárquicas o antigualitarias de la tradición, la existencia de prácticas igualitarias o democráticas dentro de la propia tradición (independientemente por ende de Occidente o de la tradición liberal); o sea, la "propia" tradición deja de ser monolítica y se abre a una pluralidad de interpretaciones.

Sin embargo, en los dos casos, incluso si con diferencias notorias, la cuestión de la validez de la democracia o el valor de la igualdad se disuelve en el problema de su oriundez. Por eso bien vistas las cosas, en América Latina, detrás de muchos elogios sobre la hibridación o el mestizaje como grandes rasgos de la civilización latinoamericana (un genio civilizatorio y una capacidad de hibridación que, notémoslo, es común a muchos otros pueblos: japoneses, iraníes, indios), subyace una obsesión por la cuestión de las raíces, por la búsqueda de prácticas políticas originales y auténticas ("en su lugar") enterradas o destruidas por la occidentalización. Una dimensión y una búsqueda que el ensayo de la identidad en su voluntad de des-encubrimiento radical no cesa de reinventar y reproducir.

Lo propio del recurso a las ideas trasplantadas por parte de la intelligentsia latinoamericana no es ni un remedo de la resistencia, ni de la frustración. Si ambas actitudes están por momentos presentes, lo esencial se juega a otro nivel: en la construcción de una tradición propiamente intelectual que procesó (o sea metabolizó) desde la conquista la historia como un proceso de encubrimiento (Dussel, 1994) al cual era necesario 
oponerle un trabajo terapéutico de descubrimiento de lo oriundo "enterrado". No se trata aquí de juzgar la pertinencia o no de esta tradición intelectual particular (cada país tiene la suya), sino comprender cómo, dentro de esta tradición, el recurso a la tesis de las ideas fuera de lugar aparece y se mantiene como un tropo analítico recurrente. En el marco de esta tradición intelectual, el derecho de inventario normativo frente a la "propia" tradición (e incluso la ruptura frente a las herencias) se subordina y a veces sacrifica en aras del combate por desentrañar lo oriundo y rechazar las ideas importadas fuera de lugar. La especificidad de la tradición de la identidad latinoamericana da así cuenta de este tercer uso recurrente de la tesis de las ideas trasplantadas.

\section{REFLEXIONES FINALES}

La crítica recurrente al liberalismo y a la modernidad en América Latina en tanto que ideas trasplantadas tiene sin duda mucho de remedo de las condenas conservadoras hacia la Revolución Francesa, no obstante, también permitieron expresar la resistencia de ciertos actores comunitarios o populares a los proyectos modernizadores. Pero la tesis de las ideas trasplantadas también ha sido popular entre las élites como una justificación a su recurrente sentimiento de fracaso y como fruto de sus representaciones del pueblo como barbarie. Por último, también presente entre los intelectuales, el recurso a esta tesis testimonia la fuerza de un pensamiento que, en torno a una tradición de la identidad, inventó y consolidó la problemática de un continente cortado de sus raíces.

He aquí las razones de la larga persistencia y seducción de las ideas trasplantadas, una tesis que fusionó las resistencias de unos, las frustraciones de otros y el sentimiento de extrañeza de terceros. Cada uno de estos actores, desde perspectivas distintas, dio cuenta de un malestar que se expresó a través de una fórmula común.

Si los tres usos son distintos, también es cierto que muchas veces se yuxtaponen, incluso cuando son realizados por actores muy diferentes entre sí. Por eso, es importante comprender que es en esta extraña comunión y conjunción de usos, más que en su pertinencia o justeza analítica, en donde reside su enigmática y durable seducción.

(Recibido el 17 de novembro de 2019)

(Reenviado el 18 de enero de 2020)

(Aprobado para su publicación el 2 de febrero de 2020) 


\section{NOTA}

1. El autor matiza su posición unas páginas después cuando reconoce que, una vez nacionalizado, el anarquismo introdujo por primera vez una politización de distintos ámbitos de la vida cotidiana (Rama, 2004:184). 


\section{BIBLIOGRAFÍA}

ALBERDI, Juan Bautista. (2008), Bases y puntos de partida para la organización política de la República argentina. Buenos Aires: Losada.

ALJOVÍN DE LOSADA, Cristóbal; ARAYA, Eduardo. (2006), "Practicas políticas y formación de ciudadanía". In: E. Cavieres F.; C. Alojín de Losada (eds.), Perú-Chile/Chile-Perú, 1820-1920. Lima: Fondo Editorial de la UNMSM, pp. 167-229.

BAYART, Jean-François. (1996), L'illusion identitaire. Paris: Fayart.

BELLO, Andrés. (2011a), "Publicidad de los juicios". In: Escritos republicanos. Santiago: LOM, pp. 73-78.

(2011b), “Constituciones”. In: Escritos republicanos. Santiago: LOM, pp. 102-108.

BIDIMA, Jean-Godefroy. (2015), La palabre. Paris: Michalon.

BONFILL BATALLA, Guillermo. (1987), México profundo. México: Grijalbo.

BOTANA, Natalio R. (2013), La tradición republicana. Buenos Aires: Edhasa. . (2012), El orden conservador. Buenos Aires: Edhasa.

BOTELHO André. (2019), "Para uma sociología política dos intellectuais". In: O retorno da sociedade. Petrópolis: Editora Vozes, pp. 220-248.

BRISSON, Thomas. (2018), Décentrer l'Occident. Paris: La Découverte.

BRUNNER, José Joaquín. (1992), América Latina: cultura y modernidad. México: Grijalbo.

BUARQUE DE HOLANDA, Sérgio. (1995), Raízes do Brasil. São Paulo: Companhia das Letras.

CEVASCO, María Elena; OHATA, Milton (orgs.). (2002), Um crítico na periferia do capitalismo. São Paulo: Companhia das Letras.

CORM, Georges. (2016), Pensée et politique dans le monde arabe. Paris: La Découverte.

CORREA SUTIL, Sonia. (2004), “El pensamiento en Chile en el siglo XX bajo la sombra de Portales”. In: O. Terán (coord.), Ideas en el siglo. Buenos Aires: Siglo XXI, pp. 211-305.

DEVÉS VALDÉS, Eduardo. (2017), Pensamiento periférico. Santiago: Ariadna Ediciones.

DUSSEL, Enrique. (1994), 1492. El encubrimiento del Otro. La Paz: Plural Editores/Universidad Mayor de San Andrés.

ESCOBAR, Arturo. (2011), Encountering development. Princeton: Princeton University Press.

FERNANDES, Florestan. (1975), A revolução burguesa no Brasil. Rio de Janeiro: Zahar.

FERRERO, Raul. (1958), El liberalismo peruano. Lima: Tipografia Peruana.

FLORES GALINDO, Alberto. (1988), Buscando un Inca. Lima: Editorial Horizonte.

GARCÍA-BRYCE WEINSTEIN, Iñigo. (2008), República con ciudadanos: los artesanos en Lima, 1821-1876. Lima: IEP.

GUERRA, François-Xavier. (2014), Modernidad e independencias. México: FCE.

HALE, Charles A. (2012), El liberalismo mexicano en la época de Mora. México: Siglo XXI. 
HALPERÍN DONGUI, Tulio. (2017), “Liberalismo argentino y liberalismo mexicano. Dos destinos divergentes". In: El espejo de la historia. Buenos Aires: Siglo XXI, pp. 143-164.

HENRÍQUEZ, Camilo. (2011), “El espíritu de imitación es muy dañoso a los pueblos”. In: Escritos republicanos. Santiago: LOM, pp. 48-52.

HIRSCHMAN, Albert. (1991), Deux siècles de rhétorique réactionnaire. Paris: Fayard.

HOBSBAWM, Eric. (1966), Les Primitifs de la révolte dans l'Europe moderne. Paris: Fayard.

; RANGER, Terence. (2012), La invención de la tradición. Barcelona: Crítica.

IKEGAMI, Eiko. (2012), La domesticación del samurái. Barcelona: Anthropos.

JAURETCHE, Arturo. (1984), FORJA y la década infame. Buenos Aires: Peña Lillo.

KNIGHT, Alan. (1985), “El liberalismo mexicano desde la Reforma hasta la revolución (una interpretación)". Historia Mexicana, vol. 35, nº I, pp. 59-91.

LASTARRIA, José Victorino. (2011), “La reforma política, única salvación de la Republica, único medio de plantear la semecracia o el gobierno de sí mismo". In: Escritos republicanos. Santiago: LOM, pp. 134-154.

MALLON, Florencia. (1995), Peasant and Nation. Berkeley: University of California Press.

MARIÁTEGUI, José Carlos. (1987), Ideología y política. Lima: Amauta.

MARTUCCELLI, Danilo. (2020), Introducción heterodoxa a las ciencias sociales. Buenos Aires: Siglo XXI.

MARUYAMA, Masao. (2018), Essais sur l'histoire de la pensée politique au Japon. Paris: Les Belles Lettres.

McEVOY, Carmen. (2011), “De la República jacobina a la República práctica: los dilemas del liberalismo en el Perú, 1822-1872". In: I. Jaksic; E. Posada Carbó (eds.), Liberalismo y poder. Santiago de Chile: FCE, pp. 207-244.

MÉNDEZ, Cecilia. (2014), La República plebeya. Lima: IEP.

MISHRA, Pankaj. (2017), Age of Anger. London: Allen Lane.

MORANDÉ, Pedro. (1984), Cultura y modernización en América Latina. Santiago: Instituto de Sociología-Universidad Católica de Chile.

MORISHIMA, Michio. (1982), Why has Japan "succeded"? Western Technology and the Japanese Ethos. Cambridge: Cambridge University Press.

PALTI, Elías J. (2014), ¿Las ideas fuera de lugar? Buenos Aires: Prometeo Libros.

RAMA, Ángel. (2004), La ciudad letrada. Santiago de Chile: Tajamar Editores.

RAMOS, Julio. (2009), Desencuentros de la modernidad en América Latina. Caracas: Fundación Editorial El Perro y la Rana.

RAMOS, Santiago. (2017), Republicanismo popular. Escritos de Santiago Ramos, "El Quebradino" (edición a cargo de Vasco Castillo y Camilo Fernández). Santiago: LOM.

ROJAS MIX, Miguel. (2018), Los cien nombres de América Latina. Santiago: Pehuén Editores.

SABATO, Hilda. (2018), Republics of the New World. Princeton: Princeton University Press. 
Danilo Martuccelli

SANDERS, James E. (2004), “Citizens of a free people: popular liberalism and race in nineteenth-century Southwestern Colombia". Hispanic American Historical Review, vol. 84, no 2, pp. 277-313.

SARMIENTO, Domingo Faustino. (2008), El Facundo. Madrid: Cátedra.

SCHWARZ, Roberto. (2012), "Las ideas fuera de lugar: algunas aclaraciones cuatro décadas después". Anuario de Investigación e Información del Centro de Documentación e Investigación de la Cultura de Izquierdas - CeDInCI, Buenos Aires, no 10-11-12 (2011-2012), pp. 25-27.

. (2000), “As idéias fora do lugar". In: Ao vencedor as batatas. San Paulo : Livraria Duas Cidades, pp. 9-32.

SEN, Amartya. (2006), La démocratie des autres. Paris : Rivages Poches.

SOUYRI, Pierre-François. (2016), Moderne sans être occidental. Paris : Gallimard.

STEVENS, Bernard. (2018), Maruyama Masao. Un regard japonais sur la modernité. Paris: CNRS Ediitons.

THOMPSON, Edward P. (1988), La formation de la classe ouvrière anglaise. Paris: Éditions de la MSH.

VALLENILLA LANZ, Laureano. (1991), "Las constituciones de papel y las constituciones orgánicas". In: Cesarismo democrático y otros textos. Caracas: Biblioteca Ayacucho, pp. 186-195.

VÉLIZ, Claudio. (2011), Los dos mundos del nuevo mundo. Santiago: Tajamar Editores.

ZEA, Leopoldo. (1965), El pensamiento latinoamericano. México: Ed. Formaca. 


\section{RESUMO \\ Crítica da Tese das Ideias Transplantadas. Atores e Estratégias}

O artigo propõe uma interpretação da permanência da tese das ideias transplantadas na América Latina. Para fazê-lo, indo mais além de questões hermenêuticas, o artigo foca no perfil de seus três principais defensores - opositores, liberais e intelectuais - e em suas diferentes estratégias com respeito ao liberalismo e à modernidade. Para os primeiros, as ideias liberais seriam estranhas à América Latina e sua tentativa de aplicação naturalmente causaria resistências. Para os segundos, as ideias liberais - que eram orgânicas na Europa e em consonância com as necessidades da expansão do capitalismo - teriam se revelado impotentes perante a realidade dos povos da região. Para os terceiros, o atraso entre as ideias e a realidade seria permanente por causa de distintos processos de encobrimento histórico do verdadeiro ser destes povos. Esta heterogênea conjunção de usos muito diferentes é a que dá conta da durável sedução da fórmula.

Palavras-chave: ideias; liberalismo; tradição; encobrimento; América Latina

\section{ABSTRACT \\ Criticism on the Transplanted Ideas Thesis. Actors and Strategies}

This article proposes an interpretation of the permanence of the transplanted ideas thesis in Latin America. To do so, going beyond hermeneutic issues, the article focuses on the profile of its three main defenders - opponents, liberals, and intellectuals - and on their different strategies with respect to liberalism and modernity. For the former, liberal ideas are foreign to Latin America and the attempt to implement them would naturally cause resistance. For the second group, liberal ideas - which were organic in Europe and in line with the needs of expansion by capitalism - would have proved powerless in the face of the reality of the people of this region. For the latter, the delay between ideas and reality would be permanent due to different processes of historical concealment of the true being of these people. This heterogeneous conjunction of very different uses accounts for the lasting seduction of the formula.

Keywords: ideas; liberalism; tradition; Concealment; Latin America 


\section{RÉSUMÉ \\ Critique de la Thèse des Idées Transplantées. Acteurs et Stratégies}

L'article propose une interprétation de la permanence de la thèse des idées transplantées en Amérique Latine. Pour ce faire, à dehors des questions herméneutiques, l'article se concentre sur le profil de ses trois principaux défenseurs opposants, libéraux et intellectuels - et sur leurs différentes stratégies en matière de libéralisme et de modernité. Pour les premiers, les idées libérales seraient étrangères à l'Amérique Latine et leur tentative de les appliquer susciterait naturellement une résistance. Pour les libéraux , les idées libérales - qui auraient été organiques en Europe et en phase avec les besoins de l'expansion du capitalisme - se seraient révélées impuissantes face à la réalité des peuples de la région. Pour certains intellectuels , l'écart entre les idées et la réalité serait permanente en raison de différents processus de dissimulation historique de l'être véritable de ces peuples. C'est cette conjonction hétérogène d'usages très différents qui explique la séduction durable de la formule.

Mots-clés: idées; libéralisme; tradition; dissimulation; Amérique Latine

\section{RESUMEN}

Crítica de la Tesis de las Ideas Trasplantadas. Actores y Estrategias

El artículo propone una interpretación de la permanencia de la tesis de las ideas trasplantadas en América Latina. Para hacerlo, descentrándose de cuestiones hermenéuticas, el artículo se centra en el perfil de sus tres principales defensores - opositores, liberales e intelectuales - y en sus diferentes estrategias con respecto al liberalismo y a la modernidad. Para los primeros, las ideas liberales serían extrañas a América Latina y su intento de aplicación despertaría naturalmente resistencias. Para los segundos, las ideas liberales - que habrían sido orgánicas en Europa y en consonancia con las necesidades de la expansión del capitalismo - se habrían revelado impotentes ante la realidad de los pueblos de la región. Para los terceros, el desfase entre las ideas y la realidad sería permanente a causa de distintos procesos de encubrimiento histórico del verdadero ser de estos pueblos. Es esta heterogénea conjunción de usos muy diferentes que da cuenta de la durable seducción de la fórmula.

Palabras clave: ideas; liberalismo; tradición; encubrimiento; Latinoamérica 